\title{
Multi-Criteria Decision Making and Numerical Optimization Approaches for Optimizing Water Loss Management Strategies in Water Distribution System - A case of Urban Water Supply and Sanitation Authorities in Tanzania
}

\author{
Maselle Joseph Kadenge ${ }^{\mathrm{a}^{*}}$, Mashaka Mkandawile ${ }^{\mathrm{b}}$,Verdiana Grace Masanja $^{\mathrm{c}}$ \\ ${ }^{a c}$ Department of Applied Mathematics and Computational Science, \\ Nelson Mandela Institution of Science and Technology, P.O.BOX 447, Arusha, Tanzania. \\ ${ }^{b}$ Department of Mathematics, University of Dar es Salaam, P.O.BOX 35091 Dar es Salaam, Tanzania.
}

Received: 26 August 2019; Accepted: 23 October 2019; Published: 08 February 2020

\begin{abstract}
Water loss in water distribution systems (WDS) is a serious problem in Tanzania and the third world countries at large. A lot of water is lost on its way before reaching the consumers. This causes a shortage of water supply which leads to loss of revenues of the concerned water authorities. The control or reduction of water loss in the WDS is closely dependent on the commitment of the decision-makers and on the strategies and budget, they set for that purpose. This paper presents a combined model of Multi-Criteria Decision Making (MCDM) and Numerical optimization techniques which may help decision-makers to prioritize and select the best strategies to be used in the management of water loss in the WDS at Moshi Urban Water Supply and Sanitation Authority (MUWSA), Tanzania. The Multi-Criteria Decision Making family methods namely the Multi-Attribute Value Theory (MAVT), Simple Multi-Attribute Rating Technique Exploiting Ranks (SMARTER), and Complex Proportional Assessment (COPRAS) were used to evaluate and prioritize the strategies, whereas the Integer Linear Programming (ILP) technique a numerical optimization technique was used to select the best strategies or alternatives to be employed in water loss management. The results show that the most preferable alternative is replacement of dilapidated pipes while the least preferable alternative is network zoning. The model selects thirteen out of sixteen alternatives, which cost 97\% (TZS 235.71 million) of the total budgets set by the water authority to form a portfolio of the best alternatives for water loss management. Furthermore, the model showed robustness as the selected portfolio of alternatives remained the same even when the weights of the evaluation criteria changed.
\end{abstract}

Index Terms: Multi-Attribute Value Theory, Integer Linear Programming, SMARTER, COPRAS, MUWSA.

(C) 2020 Published by MECS Publisher. Selection and/or peer review under responsibility of the Research Association of Modern Education and Computer Science

\footnotetext{
* Corresponding author.
}

E-mail address: 


\section{Introduction}

\subsection{Background Information}

Developing countries worldwide are facing big challenges in water management due to the increasing demand for urban water supply caused by industrialization, urbanization, improvement of living standards, and the impact of global warming in freshwater supply. Water demand is increasing while resources are diminishing due to population growth and urbanization. In addition to the mentioned challenges, not all water produced reaches the consumers; some amount of water is lost on the way before reaching the consumers. The loss of water is due to leakage, and theft of infrastructures [1, 2]. In Tanzania, for instance, the average of NonRevenue Water in the WDS is about $46 \%$ [3, 4] and (Ministry of water of Tanzania (MoW) report, 2014). Water loss in the distribution systems is a problem facing many water authorities in general, though in developing countries, the problem is worse, due to poor infrastructure and poor sanitation $[1,2]$.

Water loss is the difference between the water produced and water billed or consumed. Water losses in the WDS are grouped into two categories: Apparent (commercial) and real (physical) losses. Apparent losses include water theft such as illegal connection and meter tampering, meter inaccuracies, and unbilled water for firefighting and public use such as water used in public toilets. Physical losses, on the other hand, include water leakage from pipes, fittings, and joints, and water leakage from tank overflow, tank floor and walls [5]. Water leakage is the major contributing factor for water loss in WDS. About $70 \%$ of the total water loss in developing countries is caused by water leakage [2]. The leakage can be caused by the aging of pipes, poor network design and construction, damage to exposed pipes, poorly sealed connections, and theft of pipes.

There are various water loss control strategies, methodologies, and procedures set by the International Water Association (IWA). The IWA Water Loss Task Force (WLTF) developed and promote a water management approach that can be applied worldwide to reduce water loss in the distribution system and increase the revenue generation of the water companies [6]. The developed methodologies broadly focus on accurate and comprehensive metering, water balance and managing apparent and real losses. To manage real losses, the WLTF emphasizes on the use of four strategies: active leakage control, pressure management, speed, and quality repair, and infrastructure management. All these strategies should be balanced to get the most costeffective leakage management. As it is with real losses, apparent losses control, also use four basic methodologies: reduction of meter errors, reduction of human errors, reduction of a billing system error, and reduction of theft.

\subsection{Statement of the Problem}

Total water loss in WDS is the total of real and apparent losses. It represents the non-revenue water (NRW), which is the unbilled water or water which does not bring revenue to the water companies (IWA). The NRW is the indicator of efficient operation of WDS in which high NRW indicates poor performance of the WDS. Water losses negatively affect the operation of water companies as no company can operate efficiently if it does not realize all its revenue. Moreover, water losses in WDS have economic, environmental, public health and social effects. Besides, water losses in WDS reduce revenue, interrupt the quality of water, and inflate the operation and maintenance cost of the company [1,5]. Reference [1] shows that water loss in WDS worldwide ranges from $15 \%$ to $60 \%$ of the total water supply. The situation is critical in developing countries where a combination of aging infrastructure, illegal connections, and theft of pipes worsen the problem. While the World Bank (WB) recommends that NRW should be less than 23\% [1, 2], the Southern Africa countries have set a standard of $20 \%$ as optimal for a well-performing water company [1, 2] and (MoW report, (2014). In Tanzania, the average of NRW for the Urban Water Supply and Sanitation Authorities (UWSSAs) was recorded to be 46\% in 2013 (MoW report, 2014), in which Dar es Salaam Water Supply and Sewage Authority 
(DAWASA) had the highest percent of NRW (55\%), while other UWSSAs have an average of 37\% of NRW. Despite the MoW setting a target for reducing NRW from 46\% in 2013 to 25\% in 2019, water loss in the WDS is still high. The MoW in its 2019/2020 budget report shows that DAWASA has $40 \%$ of NRW while other UWSSAs have an average of 32\% of NRW. This high loss of water can be caused by poor management of the present strategies and on how to prioritize them. The control or reduction of water loss in the WDS is closely dependent on the commitment of the decision-makers and on the implementation of the present strategies and budget, they set for that purpose.

This study aims to develop a decision model to be used by managers to evaluate, prioritize and select a portfolio of the best strategies to be used in Water Loss Management (WLM). To achieve these objective, the study employed the following methods: (i) the MCDM methods combined with ILP a numerical optimization technique used to evaluate, prioritize and select the best strategies; (ii) MAVT - SMARTER the compensatory technique used to assign weights to the evaluation criteria; (iii) COPRAS method used to rank the alternatives; (iv) questionnaire and interview used to collect the data; and (v) LINDO 6.1 package software used to compute Linear programming models.

\subsection{Related Studies}

Studies on water loss problems in the WDS are of interest worldwide as the problem affects water authorities and consumers all over the world. Many studies in the aspect of technical and managerial have been done to reduce water loss in WDS, design, and operation of the WDS, and improving services. Most of the studies carried out in this area are from the points of view of science, engineering, mathematics, and operational research. The focus of these studies has mostly been on water loss control or reduction, design, and operation of WDS. This paper discusses water loss control or reduction in the aspect of management. It focuses on water loss management (WLM) in the WDS.

Studies in decision making are guided by MCDM methods. These are tools developed in the field of decision theory for resolving operation research problems, the methods form a finite number of decision alternatives in which DMs have to evaluate and rank based on the weights of the finite set of evaluation criteria. Many researchers have done researches in MCDM methods and their application in various fields, particularly in water loss, and resource management and planning. References [7, 8] show studies conducted in MCDM methods: Reference [7] compared COPRAS and ARAS (Additive Ration Assessment) methods in selecting a suitable air conditioner, the result showed that the two methods ranked the same the performance of alternatives. Reference [8] investigated the comparative performance of the weighted product model (WPM), weighted sum model (WSM), AHP, TOPSIS and COPRAS in determining the sustainable housing affordability assessment model. The comparison recommends the use of the COPRAS method due to its high potential in sustainable housing affordability. On the other hand, references [9, 10] show studies in the application of MCDM methods in water loss and resource management: Reference [9] did a comparison of compensatory and non-compensatory MCDM methods for water resources strategic management. SAW and AHP (analytical hierarchy process) represented compensatory methods and ELECTRE III (elimination and choice translating reality) represented non-compensatory methods. Results show that the ELECTRE III method has lower sensitivity than SAW and AHP methods to change in the weights. Also, the ranking obtained from the ELECTRE III method is more reliable for decision making. Reference [10] formulated a model based on a problem structuring method (PSM) and Preference Ranking Organization Method for Enrichment Evaluation (PROMETHEE), MCDM method to assess strategies used to balance water supply - demand in WDS. Results show that the model was robust for decision making. Moreover, the study summarized the studies done on water resource management using MCDM methods.

This study used the MAVT - SMARTER - COPRAS the MCDM methods integrated with ILP a numerical optimization technique to form a model that is used to evaluate, prioritize and select the best strategies (alternatives) for WLM to help decision-makers (DMs) in their planning. 


\section{Materials and Methods}

This section presents the data collection methods, the method used to formulate the model, and the instrument used to analyse the data.

\subsection{Data Collection and Analysis}

Both primary and secondary data were collected. Primary data were collected from knowledgeable and experienced DM by using questionnaire and interview tools. While secondary data was collected through the documentary review which includes reading the reports, brochures, flyers, and posters. The collected data were; the strategies/alternatives used by the company in WLM, evaluation criteria, budget for implementation, the quantity of water produced and lost, etc. Data were analysed through the MCDM family methods and ILP the numerical optimization technique and the model was solved by using LINDO 6.1 software package.

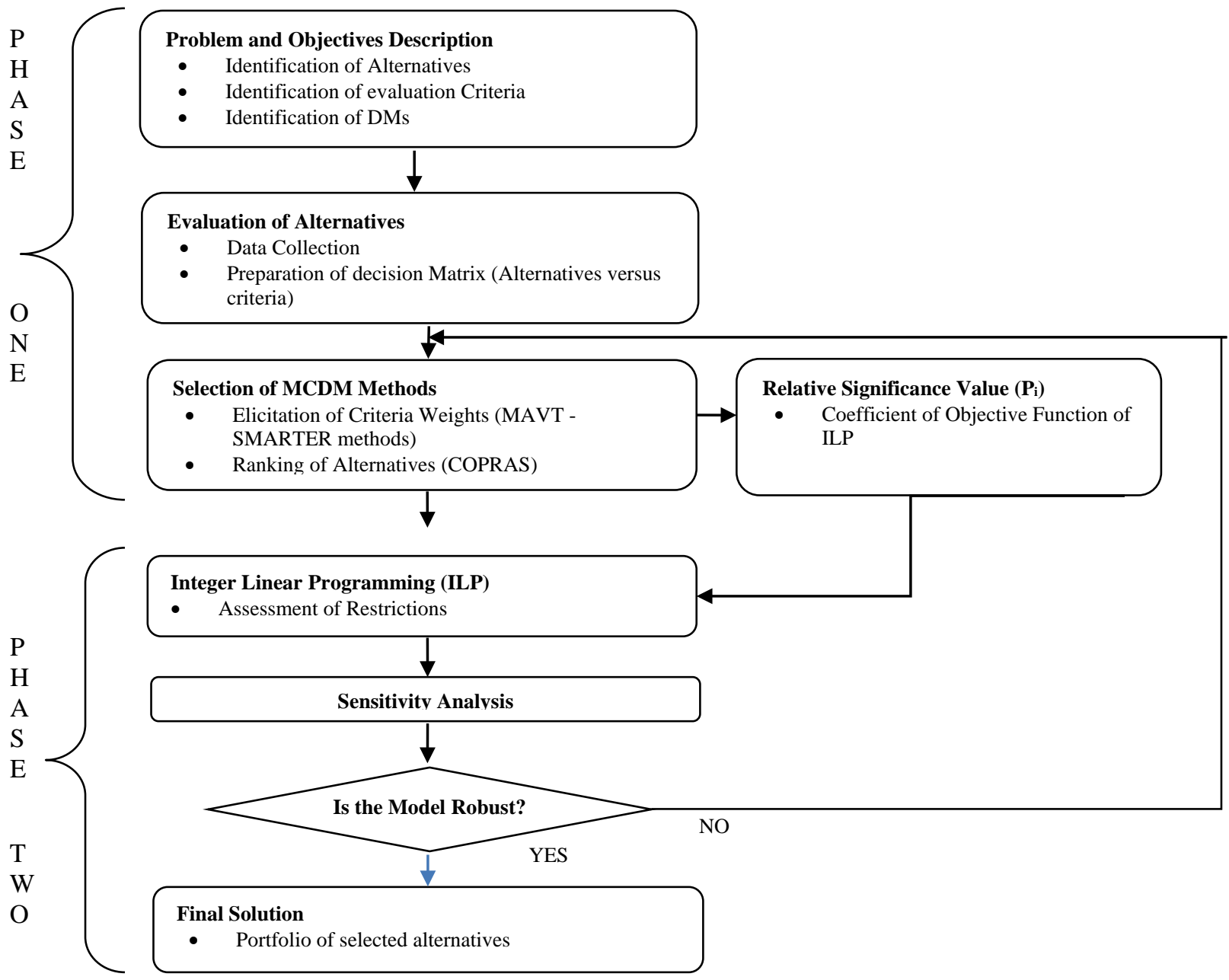

Fig.1. Workflow for formulation of the Proposed Model 


\subsection{Model Formulation}

The formulation of the model was divided into two main phases: (1) MCDM family methods approach, and (2) ILP a Numerical Optimization approach as shown in the workflow (fig.3).

\section{Results}

\subsection{Description of Problem and Objectives}

The first step in decision making is to define explicitly the problem and objectives of what is needed in the study. In doing so, the researcher identified the root causes of the problem and understood the context of the company under study. The alternatives which contribute to the achievement of the objectives and their evaluation criteria were identified. Expert DMs were engaged in the evaluation of alternatives. Thus, based on the case study, the problem of the study is the management of strategies used in controlling or reducing water loss in the WDS. The objectives are to identify, prioritize and select the portfolio of the best alternatives used at MUWSA in water loss management.

\subsubsection{Identification of Alternatives}

The surveyed alternatives for WLM in this study are:

- Alternative ( $\left.\mathbf{A}_{1}\right)$ : Education on the effective use of water which may facilitate saving water inside and outside the home, and encourage people to reports visible leaks and faults which may speed up the maintenance process and avoid excessive water loss,

$\mathrm{A}_{11}$ - Advertising campaigns

$\mathrm{A}_{12}$ - Educational campaigns in schools

$\mathrm{A}_{13}$ - Ward meetings with the society

$\mathrm{A}_{14}$ - Meeting with local leaders

- Alternative $\left(\mathbf{A}_{21}\right)$ : Illegal use control - A measure aimed at losses that occur with the illegal use of water from end-users (illegal connection, a reversal of the meter and violation of the infrastructure).

- Alternative (A31): Network zoning (Establishment of District Metering Areas -DMA)

- Alternative $\left(\mathrm{A}_{4}\right)$ : Using indicators to quantify the losses - important information for the planning of action needs to be taken to control losses.

$\mathrm{A}_{41}-24$ hours Zone Measuring (HZM)

- Alternative $\left(A_{5}\right)$ : Strategies used to control inaccuracy meter.

$A_{51}$ - Calibration of the meter

$\mathrm{A}_{52}$ - Replacement of the defect meters

- Alternative $\left(\mathrm{A}_{6}\right)$ : Detection of apparent/physical losses

$\mathrm{A}_{61}-$ Visual inspection of the WDS

$\mathrm{A}_{62}$ - comparison between the bulk water meter and customer water meter readings

$\mathrm{A}_{63}$ - Report from the community on the detected leak through a toll-free telephone

- Alternative (A $\left.\mathbf{A}_{71}\right)$ : Replacement of dilapidated pipes

- Alternative (A81): Installation of quality pipes

- Alternative (A91): Timely repair of pipe leaks (active leakage control)

- Alternative ( $\left.\mathbf{A}_{101}\right)$ : Pressure management 


\subsubsection{Evaluation Criteria}

The identified evaluation criteria to this study are;

- Criteria $\left(\mathbf{C}_{1}\right)$ : Revenue generation - The ability of alternatives to improve revenue. The higher the score value, the most preferable the alternative is.

- Criteria $\left(\mathbf{C}_{2}\right)$ : Investment cost- cost needed to implement the alternatives. The lower the score value (cost) the most preferable the alternative is.

- Criteria $\left(\mathbf{C}_{3}\right)$ : Operation \&Maintenance cost - The cost related to the implementation of the alternative. The lower the score value (cost) the most preferable the alternative is.

- Criteria $\left(\mathbf{C}_{4}\right)$ : Saving of Water - The ability of alternatives to reduce water loss. The higher the score value, the most preferable the alternative is.

- Criteria $\left(\mathbf{C}_{5}\right)$ : Quality of Water - The ability of the alternatives to retaining water quality. The higher the score value, the most preferable the alternative is.

- Criteria ( $\left.\mathbf{C}_{6}\right)$ : Water Supply reliability - The ability of alternatives to reduce supply disruptions. The fewer the frequency of disruptions (burst, leaks, and illegal uses) the most preferable the alternative is.

- Criteria $\left(\mathbf{C}_{7}\right)$ : Efficiency of the alternatives to reduce water losses. The higher the score value, the most preferable the alternative is.

\subsubsection{Identification of the DM}

This study considered only one DM who is knowledgeable and experienced in both technical and managerial issues.

TABLE 1: SCORE EVALUATION MATRIX: AlTERNATIVES VERSUS CRITERIA

\begin{tabular}{|c|c|c|c|c|c|c|c|}
\hline \multirow[t]{2}{*}{ Alternative } & \multicolumn{7}{|c|}{ Criteria } \\
\hline & $\mathrm{C}_{1}$ & $\mathrm{C}_{2}$ & $\mathrm{C}_{3}$ & $\mathrm{C}_{4}$ & $\mathrm{C}_{5}$ & $\mathrm{C}_{6}$ & $\mathrm{C}_{7}$ \\
\hline$A_{11}$ & 4 & 3 & 2 & 4 & 3 & 3 & 4 \\
\hline$A_{12}$ & 3 & 1 & 1 & 3 & 3 & 3 & 3 \\
\hline$A_{13}$ & 5 & 2 & 2 & 5 & 3 & 3 & 4 \\
\hline$A_{14}$ & 4 & 2 & 2 & 4 & 3 & 3 & 4 \\
\hline$A_{21}$ & 4 & 3 & 2 & 4 & 2 & 3 & 3 \\
\hline$A_{31}$ & 4 & 3 & 2 & 4 & 2 & 2 & 3 \\
\hline$A_{41}$ & 4 & 2 & 1 & 4 & 2 & 3 & 3 \\
\hline$A_{51}$ & 5 & 3 & 2 & 5 & 1 & 2 & 4 \\
\hline$A_{52}$ & 5 & 4 & 2 & 5 & 1 & 2 & 4 \\
\hline$A_{61}$ & 4 & 2 & 1 & 4 & 3 & 3 & 4 \\
\hline$A_{62}$ & 4 & 1 & 1 & 4 & 3 & 3 & 4 \\
\hline$A_{63}$ & 4 & 2 & 1 & 4 & 3 & 3 & 4 \\
\hline$A_{71}$ & 5 & 4 & 2 & 5 & 4 & 4 & 4 \\
\hline$A_{81}$ & 4 & 4 & 2 & 4 & 4 & 4 & 4 \\
\hline$A_{91}$ & 4 & 3 & 3 & 4 & 4 & 4 & 4 \\
\hline$A_{101}$ & 4 & 3 & 1 & 4 & 3 & 3 & 3 \\
\hline Max/Min & Max & Min & Min & Max & Max & Max & Max \\
\hline
\end{tabular}




\subsection{Evaluation of Alternatives}

The DM filled the questionnaire to evaluate the Alternatives against the Criteria. The score of each criterion over the alternatives was given according to the Likert scale as 5 - very high; 4 - high; 3 - fair; 2 low; and 1 - very low. Table 1 shows the scores of Alternatives given by the DM against each Criterion.

\subsection{Normalization of data}

Normalization of the data was done to converts the data to the commensurable unit. Normalization for the selected ranking method (COPRAS) is done without converting the cost criteria to benefit criteria by linear transformation - sum method [11, 12].

$$
a_{i j}=\frac{x_{i j}}{\sum_{i=1}^{m} x_{i j}}
$$

Where $\boldsymbol{x}_{\boldsymbol{i} \boldsymbol{j}}$ is the score of $\boldsymbol{i}$-th alternative concerning $\boldsymbol{j}$-th criterion before normalization, and $\boldsymbol{a}_{\boldsymbol{i} \boldsymbol{j}}$ is the normalized value.

The normalization process converts the values of alternatives to a range between 0 and 1 , where 0 is the worst alternative value and 1 the best alternative value in each attribute if its goal is to maximize or minimize [13].

Tables 2 shows the normalized values for the score data obtained through equation (1).

TABLE 1: NORMALIZED VALUE MATRIX: ALTERNATIVES VERSUS CRITERIA

\begin{tabular}{|c|c|c|c|c|c|c|c|}
\hline \multirow[b]{2}{*}{ Alternative } & \multicolumn{7}{|c|}{ Criteria } \\
\hline & $c_{1}$ & $c_{2}$ & $c_{3}$ & $c_{4}$ & $c_{5}$ & $c_{6}$ & $c_{7}$ \\
\hline$A_{11}$ & 0.05970 & 0.07143 & 0.07407 & 0.05970 & 0.06818 & 0.06250 & 0.06780 \\
\hline$A_{12}$ & 0.04478 & 0.02381 & 0.03704 & 0.04478 & 0.06818 & 0.06250 & 0.05085 \\
\hline$A_{13}$ & 0.07463 & 0.04762 & 0.07407 & 0.07463 & 0.06818 & 0.06250 & 0.06780 \\
\hline$A_{14}$ & 0.05970 & 0.04762 & 0.07407 & 0.05970 & 0.06818 & 0.06250 & 0.06780 \\
\hline$A_{21}$ & 0.05970 & 0.07143 & 0.07407 & 0.05970 & 0.04545 & 0.06250 & 0.05085 \\
\hline$A_{31}$ & 0.05970 & 0.07143 & 0.07407 & 0.05970 & 0.04545 & 0.04167 & 0.05085 \\
\hline$A_{41}$ & 0.05970 & 0.04762 & 0.03704 & 0.05970 & 0.04545 & 0.06250 & 0.05085 \\
\hline$A_{51}$ & 0.07463 & 0.07143 & 0.07407 & 0.07463 & 0.02273 & 0.04167 & 0.06780 \\
\hline$A_{52}$ & 0.07463 & 0.09524 & 0.07407 & 0.07463 & 0.02273 & 0.04167 & 0.06780 \\
\hline$A_{61}$ & 0.05970 & 0.04762 & 0.03704 & 0.05970 & 0.06818 & 0.06250 & 0.06780 \\
\hline$A_{62}$ & 0.05970 & 0.02381 & 0.03704 & 0.05970 & 0.06818 & 0.06250 & 0.06780 \\
\hline$A_{63}$ & 0.05970 & 0.04762 & 0.03704 & 0.05970 & 0.06818 & 0.06250 & 0.06780 \\
\hline$A_{71}$ & 0.07463 & 0.09524 & 0.07407 & 0.07463 & 0.09091 & 0.08333 & 0.06780 \\
\hline$A_{81}$ & 0.05970 & 0.09524 & 0.07407 & 0.05970 & 0.09091 & 0.08333 & 0.06780 \\
\hline$A_{91}$ & 0.05970 & 0.07143 & 0.11111 & 0.05970 & 0.09091 & 0.08333 & 0.06780 \\
\hline$A_{101}$ & 0.05970 & 0.07143 & 0.03704 & 0.05970 & 0.06818 & 0.06250 & 0.05085 \\
\hline Sum & 1.00000 & 1.00000 & 1.00000 & 1.00000 & 1.00000 & 1.00000 & 1.00000 \\
\hline Max/Min & Max & Min & Min & Max & Max & Max & Max \\
\hline
\end{tabular}




\subsection{Selection of MCDM Methods}

This stage describes the elicitation of weights to criteria and ranking of Alternatives by using MCDM methods. In this study, Multi-Attribute Value Theory (MAVT), a Multi-Attribute Utility (MAU) family method was chosen. The MAVT uses Simple Multi-Attribute Ranking Technique Exploiting Ranks (SMARTER) to assign weights to criteria basing on their importance as put by the DMs [14]. Ranking of Alternatives was done by COPRAS (COmplex PRopotional ASsessment) method. This is one of the methods used for ranking in the MAU family methods. Other MAU family methods used for ranking of alternatives are SAW (Simple Additive Weighting method) and TOPSIS (Technique for Order Preference by Similarity to Ideal Solution) [15]

\subsubsection{Elicitation of weights}

SMARTER was chosen because it uses a swing procedure to obtain a constant scale and use linear function values for intra- criterion evaluation. Furthermore, SMARTER is more precise in generating weights to the criteria than the weights of criteria given by the DMs. References [14, 16] identifies common methods in which SMARTER uses in generating the weights to the evaluation criteria: Rank Order Centroid (ROC) weights, Rank Sum (RS) weights, and Rank Reciprocal (RR) weights. The criteria are assigned with weights with vector, $W=\left[W_{1}, W_{2}, . . W_{n}\right]$, in which $W_{1}>W_{2}>W_{3}>W_{4}>\ldots>W_{n}$, which satisfies,

$$
\sum_{j=1}^{n} W_{j}=1
$$

In this study, the ROC weights method was selected to calculate the weights of criteria because weights of this method represent the centroid (centre of mass) of the simplex defined by the ranking of the criteria. Moreover, for many criteria, the method has much less error for ranked criteria and has a clear statistic basis [16]. The ROC weights are given by:

$$
\begin{aligned}
& W_{i}(R O C)=\frac{1}{n} \sum_{j=1}^{n} \frac{1}{j} \\
& i=1,2,3, \ldots . ., n
\end{aligned}
$$

Where $\mathrm{n}$ is the number of criteria; i represent the rank

Thus, the weights generated by the SMARTER - ROC weights method for seven criteria are;

$$
W_{1}=0.3704, W_{2}=0.2276, W_{3}=0.1561, W_{4}=0.1085, W_{5}=0.0728, W_{6}=0.0442, W_{7}=0.0204
$$

The DM ranked the evaluation criteria as $C_{1}>C_{4}>C_{7}>C_{3}>C_{2}>C_{6}>C_{5}$.

This means that; $C_{1} \rightarrow W_{1}, C_{4} \rightarrow W_{2}, C_{7} \rightarrow W_{3}, C_{3} \rightarrow W_{4}, C_{2} \rightarrow W_{5}, C_{6} \rightarrow W_{6}, C_{5} \rightarrow W_{7}$.

The weighted normalized values are calculated by the MAVT weighted normalized value function which is given by:

$$
V_{i j}(a)=w_{j} a_{i j} \quad i=1,2, \ldots, n
$$

Where: $\boldsymbol{w}_{\boldsymbol{j}}$ is the weight of $\boldsymbol{j}$ criteria and $a_{i j}$ is the normalized value of alternative $\boldsymbol{i}$ concerning criterion $\boldsymbol{j}$.

Table 3 shows the weighted normalized values obtained through equation (4). 
TABLE 3: WEIGHTED NORMALIZED MATRIX: ALTERNATIVES VERSUS CRITERIA

\begin{tabular}{|c|c|c|c|c|c|c|c|}
\hline \multirow[t]{3}{*}{ Alternative } & \multicolumn{7}{|c|}{ Criteria } \\
\hline & \multirow{2}{*}{$\begin{array}{l}C_{1} \\
C_{7} \\
\mathrm{~W}_{1}=0.3704\end{array}$} & \multirow{2}{*}{$\begin{array}{c}\mathrm{C}_{2} \\
\mathrm{~W}_{5}=0.0728 \\
\end{array}$} & \multirow{2}{*}{$\begin{array}{r}\mathrm{C}_{3} \\
\mathrm{~W}_{4}=0.1085 \\
\end{array}$} & \multirow{2}{*}{$\begin{array}{c}\mathrm{C}_{4} \\
\mathrm{~W}_{2}=0.2276\end{array}$} & \multirow{2}{*}{$\begin{array}{r}\mathrm{C}_{5} \\
\mathrm{~W}_{7}=0.0204\end{array}$} & \multicolumn{2}{|c|}{$\mathrm{C}_{6}$} \\
\hline & & & & & & $\mathrm{w}_{6}=0.0442$ & $\mathrm{w}_{3}=0.1561$ \\
\hline$A_{11}$ & 0.02211 & 0.00520 & 0.00804 & 0.01359 & 0.00139 & 0.00276 & 0.01058 \\
\hline$A_{12}$ & 0.01659 & 0.00173 & 0.00402 & 0.01019 & 0.00139 & 0.00276 & 0.00794 \\
\hline$A_{13}$ & 0.02764 & 0.00347 & 0.00804 & 0.01699 & 0.00139 & 0.00276 & 0.01058 \\
\hline$A_{14}$ & 0.02211 & 0.00347 & 0.00804 & 0.01359 & 0.00139 & 0.00276 & 0.01058 \\
\hline$A_{21}$ & 0.02211 & 0.00520 & 0.00804 & 0.01359 & 0.00093 & 0.00276 & 0.00794 \\
\hline$A_{31}$ & 0.02211 & 0.00520 & 0.00804 & 0.01359 & 0.00093 & 0.00184 & 0.00794 \\
\hline$A_{41}$ & 0.02211 & 0.00347 & 0.00402 & 0.01359 & 0.00093 & 0.00276 & 0.00794 \\
\hline$A_{51}$ & 0.02764 & 0.00520 & 0.00804 & 0.01699 & 0.00046 & 0.00184 & 0.01058 \\
\hline$A_{52}$ & 0.02764 & 0.00693 & 0.00804 & 0.01699 & 0.00046 & 0.00184 & 0.01058 \\
\hline$A_{61}$ & 0.02211 & 0.00347 & 0.00402 & 0.01359 & 0.00139 & 0.00276 & 0.01058 \\
\hline$A_{62}$ & 0.02211 & 0.00173 & 0.00402 & 0.01359 & 0.00139 & 0.00276 & 0.01058 \\
\hline$A_{63}$ & 0.02211 & 0.00347 & 0.00402 & 0.01359 & 0.00139 & 0.00276 & 0.01058 \\
\hline$A_{71}$ & 0.02764 & 0.00693 & 0.00804 & 0.01699 & 0.00185 & 0.00368 & 0.01058 \\
\hline$A_{81}$ & 0.02211 & 0.00693 & 0.00804 & 0.01359 & 0.00185 & 0.00368 & 0.01058 \\
\hline$A_{91}$ & 0.02211 & 0.00520 & 0.01206 & 0.01359 & 0.00185 & 0.00368 & 0.01058 \\
\hline$A_{101}$ & 0.02211 & 0.00520 & 0.00402 & 0.01359 & 0.00139 & 0.00276 & 0.00794 \\
\hline & Max & $\min$ & $\min$ & $\max$ & $\max$ & $\max$ & $\max$ \\
\hline
\end{tabular}

\subsubsection{Ranking of Alternatives}

The ranking of alternatives was done through Complex Proportional Assessment (COPRAS) method. COPRAS method is one among MAU methods used for ranking alternatives as explained by [17]. The method uses both the maximizing (benefits) and minimizing (costs) criteria values. The influence of maximizing and minimizing criteria on the evaluation result is considered separately [18].

The ranking process passes through the following steps:

- Firstly, we find the sum of weighted normalized values for both the maximization (Beneficial) and minimization (cost/non-beneficial) attributes.

The sums of weighted normalized values are calculated by using the following formulas:

$$
\begin{aligned}
& S_{+i}=\sum_{j=1}^{n} W_{+j} a_{+i j}=\sum_{j=1}^{n} V_{+i j}(a) \\
& S_{-i}=\sum_{j=1}^{n} W_{-j} a_{-i j}=\sum_{j=1}^{n} V_{-i j}(a)
\end{aligned}
$$

Where $S_{+i}$ and $S_{-i}$ are sums of maximizing and minimizing weighted normalized criteria respectively.

The greater the value of $\boldsymbol{S}_{+\boldsymbol{i}}$, the better is the alternative; and the lower the value of $\boldsymbol{S}_{-\boldsymbol{i}}$, the better is the alternative. The $\boldsymbol{S}_{+\boldsymbol{i}}$ and $\boldsymbol{S}_{-\boldsymbol{i}}$ values express the degree of goals attained by each alternative. The significances of the alternatives based on defining the positive alternatives $\boldsymbol{S}_{+\boldsymbol{i}}$ in equation (5) and negative alternatives $\boldsymbol{S}_{-\boldsymbol{i}}$ in equation (6) are given in Table 4. 
TABLE 4: SUMS OF THE WEIGHTED NORMALIZED VALUES

\begin{tabular}{|c|cccc|}
\hline Alternative & $\boldsymbol{S}_{+\boldsymbol{i}}$ & Value & $\boldsymbol{S}_{-\boldsymbol{i}}$ & Value \\
\hline$A_{11}$ & $S_{+11}$ & $S_{-11}$ & 0.01324 \\
$A_{12}$ & $S_{+12}$ & 0.05044 & $S_{-12}$ & 0.00575 \\
$A_{13}$ & $S_{+13}$ & 0.03887 & $S_{-13}$ & 0.01150 \\
$A_{14}$ & $S_{+14}$ & 0.05936 & $S_{-14}$ & 0.01150 \\
$A_{21}$ & $S_{+21}$ & 0.05044 & $S_{-21}$ & 0.01324 \\
$A_{31}$ & $S_{+31}$ & 0.04733 & $S_{-31}$ & 0.01324 \\
$A_{41}$ & $S_{+41}$ & 0.04641 & $S_{-41}$ & 0.00749 \\
$A_{51}$ & $S_{+51}$ & 0.04733 & $S_{-51}$ & 0.01324 \\
$A_{52}$ & $S_{+52}$ & 0.05752 & $S_{-52}$ & 0.01497 \\
$A_{61}$ & $S_{+61}$ & 0.05752 & $S_{-61}$ & 0.00749 \\
$A_{62}$ & $S_{+62}$ & 0.05044 & $S_{-62}$ & 0.00575 \\
$A_{63}$ & $S_{+63}$ & 0.05044 & $S_{-63}$ & 0.00749 \\
$A_{71}$ & $S_{+71}$ & 0.05044 & 0.01497 \\
$A_{81}$ & $S_{+81}$ & 0.06075 & $S_{-81}$ & 0.01497 \\
$A_{91}$ & $S_{+91}$ & 0.05182 & $S_{-91}$ & 0.01726 \\
$A_{101}$ & $S_{+101}$ & 0.05182 & $S_{-101}$ & 0.00922 \\
\end{tabular}

- $\quad$ Secondly, we determine the relative significances or priorities $\left(\boldsymbol{P}_{\boldsymbol{i}}\right)$ of the alternatives.

The relative significances or priorities of the alternatives are found by the relationship given below:

$$
P_{i}=S_{+i}+\frac{S_{-\min } \sum_{i=1}^{m} S_{-i}}{S_{-i} \sum_{i=1}^{m} \frac{S_{-\min }}{S_{-i}}}
$$

Where $S_{-\min }$ is the minimum value of $S_{-i}, m$ is the number of alternatives.

The equation can be simplified to

$$
P_{i}=S_{+i}+\frac{\sum_{i=1}^{m} S_{-i}}{S_{-i} \sum_{i=1}^{m} \frac{1}{S_{-i}}}
$$

The greater the value of $P_{i}$, the higher the priority of the alternative. The relative significance value of an alternative shows the degree of satisfaction attained by that alternative. The alternative with the highest relative significance value $\left(P_{\max }\right)$ is the best choice among the evaluated alternatives.

For example, $\mathrm{i}=1$

$$
\begin{aligned}
P_{1} & =S_{+1}+\frac{\sum_{i=1}^{16} S_{-i}}{S_{-1} \sum_{i=1}^{16} \frac{1}{S_{-i}}} \\
& =0.050438+\frac{0.1813}{0.013237(1591.3707626)} \\
\mathrm{P}_{1} & =0.059045
\end{aligned}
$$

Note: $\mathbf{P}_{1}=\mathbf{P}_{11}, \mathbf{S}_{+1}=\mathbf{S}_{+11}, \mathbf{S}_{-1}=\mathbf{S}_{-11}$

As shown above, the relative significance of other alternatives is calculated and shown in table 5 .

- $\quad$ Thirdly, we determine the quantitative Utility $\left(\mathrm{U}_{\mathrm{i}}\right)$ 
The quantitative utility $\left(\mathrm{U}_{\mathrm{i}}\right)$ is determined by comparing the priorities of all alternatives with the one with maximum relative significance.

$$
U_{i}=\left(\frac{P_{i}}{P_{\max }}\right) \times 100 \%
$$

The utility values of the alternatives range from $0 \%$ to $100 \%$. Table 4 shows the quantitative utility of each alternative $\left(U_{i}\right)$ about the alternative with maximum relative significance $\left(P_{\max }\right)$

TABLE 5: VALUES OF PREFERENCE (PI ), QUANTITY UTILITY (UI) AND RANKING OF ALTERNATIVE

\begin{tabular}{lccccccc}
\hline Rank & Alter & $\boldsymbol{P}_{\boldsymbol{i}}$ & $\boldsymbol{U}_{\boldsymbol{i}(\boldsymbol{\%})}$ & $\boldsymbol{R a n k}$ & Alter & $\boldsymbol{P}_{\boldsymbol{i}}$ & $\boldsymbol{U}_{\boldsymbol{i}}(\boldsymbol{\%})$ \\
\hline 1. & $\mathrm{A}_{71}$ & 0.073308 & 100.00000 & 9. & $\mathrm{~A}_{41}$ & 0.062150 & 84.77214 \\
2. & $\mathrm{A}_{62}$ & 0.070372 & 95.99498 & 10. & $\mathrm{~A}_{91}$ & 0.061041 & 83.26649 \\
3. & $\mathrm{A}_{63}$ & 0.070125 & 95.65805 & 11. & $\mathrm{~A}_{14}$ & 0.060883 & 83.05096 \\
4. & $\mathrm{A}_{13}$ & 0.069877 & 95.31974 & 12. & $\mathrm{~A}_{11}$ & 0.059045 & 80.54373 \\
5. & $\mathrm{~A}_{51}$ & 0.066524 & 90.74589 & 13. & $\mathrm{~A}_{12}$ & 0.058143 & 79.31331 \\
6. & $\mathrm{~A}_{52}$ & 0.065131 & 88.84569 & 14. & $\mathrm{~A}_{101}$ & 0.057011 & 77.76914 \\
7. & $\mathrm{~A}_{61}$ & 0.064344 & 87.77214 & 15. & $\mathrm{~A}_{21}$ & 0.056338 & 76.85109 \\
8. & $\mathrm{A}_{81}$ & 0.063692 & 86.88274 & 16. & $\mathrm{~A}_{31}$ & 0.055125 & 75.19643 \\
\hline
\end{tabular}

Basing on the results, the complete ranking of alternatives for WLM is:

$A_{71}>A_{62}>A_{63}>A_{13}>A_{51}>A_{52}>A_{61}>A_{81}>A_{41}>A_{91}>A_{14}>A_{11}>A_{12}>A_{101}>A_{21}>A_{31}$ with A71 indicating the best alternative with $100 \%$ utility degree and $\mathbf{A}_{31}$ indicating is the worst alternative with 75.19643\% utility degree.

\subsection{Integer Linear Programming (ILP)}

ILP is a mathematical optimization program in which all variables are restricted to integers. In this study, the ILP was used to assess the operational restrictions of the company and to select the portfolio of alternatives. A Special form of ILP, the Binary Integer Programming (BIP) was used. In BIP, all decision variables are restricted to take on binary values either 0 or 1[19]. The BIP gives the model more meanings in decision making. Numbers 0 or 1 in this programming represent the selection choice of alternatives instead of their arbitrary values.

For the studied problem, the developed ILP model is as follows:

\section{Objective function:}

Maximize $\quad Z=0.059045 A_{11}+0.058143 A_{12}+0.069877 A_{13}+0.060883 A_{14}+0.056338 A_{21}+$ $0.055125 A_{31}+0.062150 A_{41}+0.066524 A_{51}+0.065131 A_{52}+0.064344 A_{61}+0.070372 A_{62}+$

$0.070125 A_{63}+0.073308 A_{71}+0.063692 A_{81}+0.061041 A_{91}+0.057011 A_{101}$

\section{Subject to constraints}

$14.58 A_{11}+14.58 A_{12}+14.58 A_{13}+14.58 A_{14}+31.59 A_{21}+29.16 A_{31}+2.43 A_{41}+75.33 A_{51}+$

$75.33 A_{52}+4.86 A_{61}+4.86 A_{62}+4.86 A_{63}+29.16 A_{71}+51.03 A_{91}+4.86 A_{101} \leq 243$

$A_{11}+A_{12}+A_{13}+A_{14} \geq 1$

$A_{51}+A_{52} \geq 1$

$A_{61}+A_{62}+A_{63} \geq 1$

$A_{11}+A_{12}+A_{13}+A_{14}+A_{21}+A_{31}+A_{41}+A_{51}+A_{52}+A_{61}+A_{62}+A_{63}+A_{71}+A_{81}+A_{91}+$ $A_{101} \leq 16$

$A_{11}, A_{12}, A_{13}, A_{14}, A_{21}, A_{31}, A_{41}, A_{51}, A_{52}, A_{61}, A_{62}, A_{63}, A_{71}, A_{81}, A_{91}, A_{101}=[0$ or 1$]$ 
Where: Eq. (10) is the objective function in which the coefficients are the relative preferences $\left(\mathrm{P}_{\mathrm{i}}\right)$ of the MCDM methods. Eq. (11) is the budget restriction constraint for implementation of preventive actions which was in 1,000.000/= Tanzanian Shillings (TZS). Eqs. (12) - (14) represent the multiple-choice alternatives found in one category of strategies. The constraints ensure that at least one sub- alternative can be adopted in WLM. Eq. (15) is the constraint that represents the optimal number of alternative to be selected in a portfolio. Eq. (16) is a binary (decision variables, $A_{i}$ ) constraint; the values are integers 0 or 1 , where 1 means that $A_{i}$ is the selected alternative and 0 otherwise.

After solving the ILP model (by LINDO 6.1 software), the variables, $A_{11}, A_{12}, A_{13}, A_{14}, A_{41}, A_{51}, A_{61}$, $A_{62}, A_{63}, A_{71}, A_{81}, A_{91}$, and $A_{101}$ yielded value 1 , while variables, $A_{21}, A_{31}$, and $A_{52}$ yielded 0 value. This means variables with values 1 are alternatives selected to form a portfolio of best alternatives and those with 0 values are eliminated. The eliminated alternatives are of less importance and their roles can be performed by remaining alternatives. The selected alternatives represent a total cost of TZS 235.71 million which is $97 \%$ of the total cost budgeted by the company. This means the company will save TZS 7.29 million if the alternatives of this portfolio are implemented. The maximum sum of values of the selected alternatives is $\mathrm{Z}=0.836515$.

\subsection{Sensitivity Analysis}

Sensitivity analysis is a fundamental concept in the effective use and implementation of quantitative decision models, whose purpose is to assess the stability (robustness) of an optimal solution under changes in the parameters [20]. For that, the ranking of the criteria was changed after doing mathematical calculations which lead to the change of weights of the criteria using mathematical formulae as explained by [21] In the analysis, we find the new ranking of decision criteria as $C_{3}>C_{1}>C_{4}>C_{2}>C_{6}>C_{5}>C_{7}$.

Considering the weights of criteria generated by SMARTER- ROC method in section (3.1.1) we find: $\mathrm{C}_{3} \rightarrow \mathrm{W}_{1}, \mathrm{C}_{1} \rightarrow \mathrm{W}_{2}, \mathrm{C}_{4} \rightarrow \mathrm{W}_{3}, \mathrm{C}_{2} \rightarrow \mathrm{W}_{4}, \mathrm{C}_{6} \rightarrow \mathrm{W}_{5}, \mathrm{C}_{5} \rightarrow \mathrm{W}_{6}, \mathrm{C}_{7} \rightarrow \mathrm{W}_{7}$

Using this information, we get new values preferences $\left(\mathrm{P}_{\mathrm{i}}\right)$, quantity utilities $\left(\mathrm{U}_{\mathrm{i}}\right)$ and alternatives ranking as shown in table 6 below.

TABLE 6: PREFERENCES (PI), QUANTITY UTILITIES (UI) AND RANKING OF ALTERNATIVES

\begin{tabular}{|c|c|c|c|c|c|c|c|}
\hline Rank & Alter & $\boldsymbol{P}_{i}$ & $U_{i}(\%)$ & Rank & Alter & $\boldsymbol{P}_{i}$ & Ui(\%) \\
\hline 1. & $\mathrm{~A}_{63}$ & 0.082316 & 100.00000 & 9. & $\mathrm{~A}_{14}$ & 0.056947 & 69.18096 \\
\hline 2. & $A_{62}$ & 0.079274 & 96.30449 & 10. & $\mathrm{~A}_{51}$ & 0.056728 & 68.91491 \\
\hline 3. & $\mathrm{~A}_{12}$ & 0.073151 & 88.86608 & 11. & $\mathrm{~A}_{91}$ & 0.055844 & 67.84100 \\
\hline 4. & $\mathrm{~A}_{71}$ & 0.072301 & 87.83347 & 12. & $A_{11}$ & 0.054424 & 66.11594 \\
\hline 5. & $\mathrm{~A}_{41}$ & 0.069620 & 84.57651 & 13. & $\mathrm{~A}_{52}$ & 0.054122 & 65.74906 \\
\hline 6. & $\mathrm{~A}_{61}$ & 0.068723 & 83.48681 & 14. & $\mathrm{~A}_{21}$ & 0.053282 & 64.72861 \\
\hline 7. & $A_{81}$ & 0.064997 & 78.96035 & 15. & $A_{101}$ & 0.052977 & 64.35808 \\
\hline 8. & $\mathrm{~A}_{13}$ & 0.063123 & 76.68376 & 16. & $\mathrm{~A}_{31}$ & 0.050933 & 61.87497 \\
\hline
\end{tabular}

The new ranking of alternatives becomes:

\section{$A_{63}>A_{62}>A_{12} \succ A_{71}>A_{41}>A_{61}>A_{81}>A_{13}>A_{14}>A_{51}>A_{91}>A_{11} \succ A_{52} \succ A_{21} \succ A_{101}>A_{31}$}

Besides, by using the values of new relative significance $\left(\mathrm{P}_{\mathrm{i}}\right)$ of the alternatives, the new ILP model was formulated; and when solved the same portfolio of alternatives ( $A_{11}, A_{12}, A_{13}, A_{14}, A_{41}, A_{51}, A_{61}$, $A_{62}, A_{63}, A_{71}, A_{81}, A_{91}$, and $\left.A_{101}\right)$ was selected. This implies that the ILP model for selecting the portfolio of the best alternative is robust regardless of the ranking of alternatives and the change of weights of evaluation criteria. 


\section{Results and Discussion}

The strategies used at MUWSA to manage water losses in their WDS were investigated and evaluated. Sixteen main techniques were identified and evaluated by seven decision criteria using MCDM methods of MAVT - SMARTER - COPRAS. The values of utility (Ui) show that there are no alternatives which are below $50 \%$, meaning that all the investigated alternatives are important strategies for water loss management. The methods rank the strategy of replacement of dilapidated pipes as the best alternative and the strategy of network zoning by establishing district metering areas as the least alternative.

The optimization decision model on selecting the best strategies for WLM among those used at MUWSA was developed and analysed through the integration of MCDM methods and ILP technique and was solved using the software LINDO version 6.1. The Model selected thirteen strategies: advertising campaigns, education campaign in schools, ward meeting with the society, meeting with local leaders, Indicators for quantifying the losses, Calibration of meters, visual inspection, comparison between the bulk meter and customers' meter, report from the community, Replacement of dilapidated (decay) pipes, Installation of quality pipes, Timely repair of pipe and fitting leaks, and Pressure management. The model eliminated three strategies: Illegal control, Network zoning by establishing District Metering Areas, and replacement of defect meters. It was established that the selected strategies cost 97\% (TZS 235.71 million) of the total budgets set for water loss management by MUWSA. The authority will save 3\% (TZS 7.3 million) of its budget which can be allocated to other operational activities.

The sensitivity of the methods was analysed by changing the weights of the evaluation criteria. The model selected the same number of alternatives as those selected before changing the weights of evaluation criteria. This implies that the model is robust for selecting the best strategies applicable in WLM in the WDS.

Therefore, the MCDM methods are the best tools for prioritizing the strategies used in organization planning in UWSSAs and in other business industries. Furthermore, the ILP technique showed robustness in selecting the portfolio of best strategies used by the UWSSAs.

\section{Conclusion}

This study aimed to optimize the water loss management strategies used in the water distribution system by using MCDM and Numerical Optimization approaches to prioritize and optimize the strategies used in water loss management in the WDS. Furthermore, the study revealed that the combination of MAVT-SMARTERCOPRAS the MCDM methods and ILP a numerical optimization technique is the best approach in decision making in water resource management and other fields in the industries.

The techniques developed by this study were applied to investigate the sixteen strategies used by MUWSA administration in the management of water loss in the WDS of Moshi Municipality and the optimal alternatives have been identified, which if used they can reduce the cost incurred by MUWSA in water loss management by $3 \%$. These findings could assist water distribution authorities in a similar setting like MUWSA to select alternatives that are cost-effective. The results could also assist policymakers to implement policies of water loss management which are guided by mathematical research results.

It is therefore recommended that the same study should be done in large WDS to see how the model could improve the saved revenue. Moreover, a user-friendly application is designed which can be used by managers to enter their alternatives and get outputs of selected cost-effective ones.

\section{Acknowledgment}

This work has been supported financially by the Tanzania Bureau of Standards (TBS) and access to data by the Moshi Urban Water Supply and Sanitation Authority (MUWSA). 


\section{References}

[1] Makaya, E. (2016). Water loss management strategies for developing countries.

[2] Ndunguru, M. G. and Hoko, Z. (2016). Assessment of water loss in Harare, Zimbabwe. Journal of Water, Sanitation and Hygiene for Development. 6(4): 519-533.

[3] Mosha, H. D. (2014). Effects of Water Pipe Burst on water quality and non revenue water in Arusha city: a case study of AUWSA. The Open University of Tanzania.

[4] Mahoo, H., Simukanga, L. and Kashaga, R. (2015). Water resources management in Tanzania: Identifying research gaps and needs and recommendations for a research agenda. Tanzania Journal of Agricultural Sciences. 14(1):

[5] SELEK, B., ADIGÜZEL, A., İRITAŞ, Ö., KARAASLAN, Y., KINACI, C., MUHAMMETOĞLU, A. and MUHAMMETOĞLU, H. (2018). Management of water losses in water supply and distribution networks in Turkey. Türkiye Su Bilimleri ve Yönetimi Dergisi. 2(1): 58-75.

[6] Charalambous, B., Foufeas, D. and Petroulias, N. (2014). Leak detection and water loss management. Water Utility Journal. 8(25-30.

[7] Adali, E. A. and Işık, A. T. (2016). Air conditioner selection problem with COPRAS and ARAS methods. Manas Sosyal Araştırmalar Dergisi. 5(2): 124-138.

[8] Mulliner, E., Malys, N. and Maliene, V. (2016). Comparative analysis of MCDM methods for the assessment of sustainable housing affordability. Omega. 59(146-156.

[9] Banihabib, M. E., Hashemi-Madani, F.-S. and Forghani, A. (2017). Comparison of Compensatory and non-Compensatory Multi Criteria Decision Making Models in Water Resources Strategic Management. Water Resources Management. 31(12): 3745-3759.

[10] Cambrainha, G. M. and Fontana, M. E. (2018). A multi-criteria decision making approach to balance water supply-demand strategies in water supply systems. Production. 28(

[11] Vafaei, N., Ribeiro, R. and Camarinha-Matos, L. (2016). Normalization Techniques for Multi-Criteria Decision Making. THE EWG-DSS. 23-25.

[12] Mukhametzyanov, I. and Pamucar, D. (2018). A sensitivity analysis in MCDM problems: A statistical approach. Decision making: applications in management and engineering. 1(2): 51-80.

[13] Fontana, M. and Morais, D. (2016). Decision model to control water losses in distribution networks. Production, 26 (4), 688-697.

[14] Barfod, M. B. and Leleur, S. (2014). Multi-criteria decision analysis for use in transport decision making.

[15] Mousavi-Nasab, S. H. and Sotoudeh-Anvari, A. (2017). A comprehensive MCDM-based approach using TOPSIS, COPRAS and DEA as an auxiliary tool for material selection problems. Materials \& Design. 121(237-253.

[16] Sureeyatanapas, P. (2016). Comparison of rank-based weighting methods for multi-criteria decision making. Engineering and Applied Science Research. 43(376-379.

[17] Volvačiovas, R., Turskis, Z., Aviža, D. and Mikštienė, R. (2013). Multi-attribute selection of public buildings retrofits strategy. Procedia Engineering. 57(1236-1241.

[18] Mondal, S., Kuila, S., Singh, A. K. and Chatterjee, P. (2017). A complex proportional assessment methodbased framework for industrial robot selection problem. Int J Res Sci Eng. 3(368-378.

[19] Ghosh, S. K., Zoha, N., Chowdhury, T. Z. and Ahmmed, M. S. (2018). Supplier Selection using Integer Linear Programming Model. Global Journal of Research In Engineering.

[20] Goodridge, W. S. (2016). Sensitivity analysis using simple additive weighting method. International Journal of Intelligent Systems and Applications. 8(5): 27.

[21] Triantaphyllou, E. (2000). A Sensitivity Analysis Approach for MCDM Methods Multi-criteria Decision Making Methods: A Comparative Study (pp. 131-175): Springer. 


\section{Authors' Profiles}

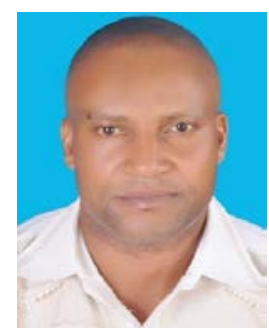

Maselle Joseph Kadenge is a graduate student at Nelson Mandela Institution of Science and Technology, Arusha, Tanzania. Currently, he is pursuing MSc. in Applied Mathematics and Computational Science. His Bachelor degree (BSc.Ed) is in Physics, Mathematics, and Education from the University of Dar es Salaam, awarded in 2006. Moreover, he has Masters of Business Administration in Corporate Management (MBACM) obtained from the Mzumbe University, Tanzania in 2010. His research interest is in Operation research.

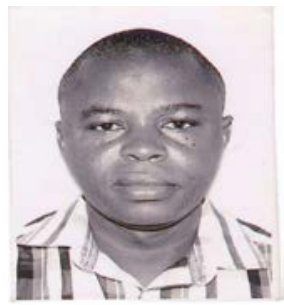

Dr. Mashaka James Mkandawile works at the University of Dar es Salaam as a Lecturer and Coordinator of Actuarial Science Programme, Department of Mathematics, College of Natural and Applied Sciences (CONAS). He obtained his PhD in Operations Research in 2015 at the University of Dar es Salaam with research work and licentiate at Umea University in Sweden. His research area includes Actuarial Science, Statistics and Probability Theories, Numerical Optimization, Graph Theory and Computer Programming.

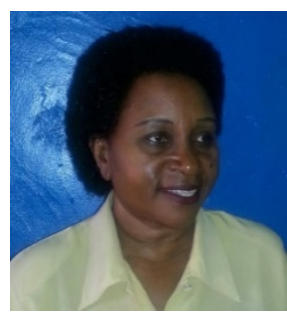

Professor Verdiana Grace Masanja works for the Nelson Mandela African Institution for Science and Technology as a Mathematics Professor. Her PhD (Doktor Ingineur) in Fluid Dynamics is from the Technische Universität Berlin (TUB) awarded in 1986. She is employed as academic faculty from Tutorial Assistant in 1976 till Full Professor in 2006, a position she holds to date. She has held academic managerial positions from Head of Department up to Deputy Vice-Chancellor level. Her research areas include problems of the flow of nanofluids and blood, modelling groundwater, sediment transport, sewage, and clean water distribution systems, and modelling transmission dynamics of diseases of plants, wildlife, and livestock and their vectors and bacteria/ viruses.

How to cite this paper: Maselle Joseph Kadenge, Mashaka James Mkandawile, Verdiana Grace Masanja, " Multi-Criteria Decision Making and Numerical Optimization Approaches for Optimizing Water Loss Management Strategies in Water Distribution System - A case of Urban Water Supply and Sanitation Authorities in Tanzania ", International Journal of Mathematical Sciences and Computing(IJMSC), Vol.6, No.1, pp.10-24, 2020. DOI: 10.5815/ijmsc.2020.01.02 